\title{
Customers'
}

\section{Perceptions of Best Available Hotel Rates}

\author{
by KRISTIN V. ROHLFS and SHERYL E. KIMES
}

A study of 153 travelers in three airports (Dallas, Pittsburgh, and Ithaca) found that respondents held a generally negative view of hotel companies' pricing policies. The respondents were asked specifically about their reaction to best available rate pricing, as compared to the common practice of quoting a single rate for a multiple-night stay. Compared to the singlerate policy, respondents judged that being charged the lowest possible rate for each night is more fair, more acceptable, more reasonable, and more honest, even if the room rate changes from night to night. In particular, infrequent travelers (those staying in hotels twenty nights per year or less) judged best rate pricing most favorably. In contrast, frequent travelers were essentially indifferent to the two pricing approaches.

Keywords: revenue management; pricing; fairness

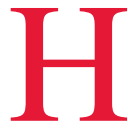

otel guests have noticed that most hotels' prices are continually in flux, due to the dictates of revenue management. In particular, customers have caught on to the possibility that a hotel will offer a lower rate after they have booked. Thus, many customers compare the rates offered on the hotel chain's web site with those of third-party distributors in a quest for the lowest rates. In this article, we examine a mechanism that is intended to restrict guests' shopping activities, namely, the best available rate (BAR) guarantee.

A relatively new pricing technique used by both hotel chains and web-based reservation intermediaries, BAR pricing, entails quoting a specific rate for each night of a multiple-night hotel stay. Typically, some form of incentive attaches to the rates thus offered to assure customers that they are, indeed, receiving the lowest rate available for the date in question. BAR pricing stipulates that customers making a reservation through a certain distribution channel, usually the internet, are quoted and guaranteed the lowest available rate each night for the specific arrival date, length of stay, and room type. 
Although simple in principle, BAR pricing is not without difficulties. Recent research has addressed the value of the guarantee attached to BAR prices and how service companies can structure guarantees (Carvell and Quan 2005; Marcus and Anderson 2006). Moreover, articles in the popular press have highlighted problems that customers have had with actually enacting the BAR guarantees (Gilden 2005, 2004). Given the relative novelty of BAR pricing, we sought to gauge customers' perceptions of and reactions to the presentation of the prices behind these guarantees. In particular, we wanted to determine whether customers actually liked the idea of paying different rates for each night of a hotel stay, on the assumption that they are paying the lowest rate. On the other hand, perhaps customers prefer the long-standing practice of being quoted an average rate for their stay, even though that rate is not necessarily the lowest price for every night of their stay.

\section{Best Available Rate Pricing}

As far as we know, Hotels.com introduced BAR pricing about five years ago to gain a competitive edge over other thirdparty intermediaries, such as Expedia, Priceline, and Orbitz. Not surprisingly, these competitors responded by also instituting their own best rate pricing and guarantees (see Exhibit 1). The characteristics of the various companies' BAR guarantees and pricing policies are roughly identical. The sites quote customers the lowest available nightly rate for a specific room type, arrival date, and length of stay, while the rules of the guarantee require a prepaid reservation and the guarantee only applies if a lower rate is found on that web site or that of a direct competitor, such as another intermediary or the hotel chain itself. Auction sites, Hotwire, and the like are not covered by the guarantee.

It did not take long for hotel chains also to adopt BAR pricing. The chains instituted their best rate policies initially to ensure that individual properties were not undercutting rates offered by internet intermediaries or violating pricing agreements made between chains and intermediaries to sell distressed inventory. As BAR pricing made nightly room rates more transparent to customers, however, hotels chains also began to use BAR pricing and associated guarantees to direct bookings to the hotel's web site and away from the third-party vendors (KPMG 2004). Many hotel chains offer various versions of BAR pricing and BAR guarantees, as shown in Exhibit 1.

Despite the wide dispersion of BAR pricing, hotel rates are rarely consistent over all distribution channels (KPMG 2004; Thompson and Failmezger 2005). Moreover, the practice is still new enough that it is worthwhile to find out how would-be guests react to BAR pricing. In this way, hoteliers can develop appropriate rate-quoting policies.

The most noticeable difference between traditional hotel room pricing and BAR pricing is that under a BAR policy customers who are staying for more than one night probably will pay a different price each night. In contrast, the traditional oneprice approach for multiple nights means that the guest may pay more than the lowest rate for some nights, even if lower rates were available on particular days of the stay. On the other hand, depending on how the revenue management system operates, the guest may also pay less than the lowest rate for certain nights. Here is how that works. Suppose that a customer requested a reservation for a three-night midweek stay and the hotel's revenue management system indicated that the lowest price for the first two nights was $\$ 205$, but the lowest price for the third night was $\$ 175$. The hotel's pricing policy might suggest that the guest be quoted either a nightly rate of $\$ 205$, or the average of those nightly rates, $\$ 195$. This pricing approach stems from 


\section{Exhibit 1:}

Sample of Best Available Rate (BAR) Policies

\begin{tabular}{|c|c|c|}
\hline Company & BAR Policy & Selected Policy Specifics \\
\hline \multicolumn{3}{|c|}{ Third-party reservation web sites } \\
\hline \multirow[t]{3}{*}{ Hotels.com } & $\begin{array}{l}\text { Lowest available rate } \\
\text { guarantee for prepaid }\end{array}$ & $\begin{array}{l}\text { Guarantee is not valid for certain properties and } \\
\text { does not apply to special events }\end{array}$ \\
\hline & reservations & $\begin{array}{l}\text { Customer must find lower rate within } 24 \text { hours of } \\
\text { booking }\end{array}$ \\
\hline & & $\begin{array}{l}\text { Hotels.com will refund the difference between rates } \\
\text { or will cancel the reservation without penalty }\end{array}$ \\
\hline \multirow[t]{2}{*}{ Expedia } & Low-price guarantee for & Available only for special-rate hotels \\
\hline & prepaid reservations & $\begin{array}{l}\text { Customer must find lower rate online within } \\
24 \text { hours of booking and provide URL of web site } \\
\text { Expedia will refund the difference }\end{array}$ \\
\hline \multirow[t]{2}{*}{ Travelocity } & $\begin{array}{l}\text { GoodBuy guarantee for } \\
\text { prepaid reservations }\end{array}$ & $\begin{array}{l}\text { Customer must find lower rate online only within } \\
24 \text { hours of booking }\end{array}$ \\
\hline & & $\begin{array}{l}\text { Travelocity will pay the difference between rates or } \\
\text { will refund reservation and allow cancellation } \\
\text { without fee }\end{array}$ \\
\hline \multirow[t]{2}{*}{ Orbitz } & $\begin{array}{l}\text { OrbitzSaver rate guarantee } \\
\text { for prepaid reservations }\end{array}$ & $\begin{array}{l}\text { Customer must find lower rate on another web site } \\
\text { within } 24 \text { hours of booking and must provide URL }\end{array}$ \\
\hline & & $\begin{array}{l}\text { Orbitz will refund the difference but is not } \\
\text { responsible for posting incorrect rates }\end{array}$ \\
\hline \multirow[t]{2}{*}{ Priceline } & $\begin{array}{l}\text { Lowest possible price } \\
\text { guarantee for prepaid } \\
\text { reservations }\end{array}$ & $\begin{array}{l}\text { Customer must find lower rate on another web site } \\
\text { within } 24 \text { hours of booking and rate must be } \\
\text { available to Priceline representative }\end{array}$ \\
\hline & & $\begin{array}{l}\text { Priceline will refund the difference; limited to one } \\
\text { refund per } 6 \text {-week period }\end{array}$ \\
\hline \multicolumn{3}{|c|}{ Hotel chain web sites } \\
\hline \multirow[t]{3}{*}{ Marriott } & $\begin{array}{l}\text { Look no Further best } \\
\text { rate guarantee for all } \\
\text { reservations }\end{array}$ & $\begin{array}{l}\text { Customer must find lower rate through any } \\
\text { reservation channel within } 24 \text { hours of booking } \\
\text { Marriott will honor the lower rate and give an addi- } \\
\text { tional } 25 \text { percent discount }\end{array}$ \\
\hline & & $\begin{array}{l}\text { Lower rates cannot be acquired through opaque, or } \\
\text { auction, web sites such as Hotwire }\end{array}$ \\
\hline & & $\begin{array}{l}\text { Each night of a multiple night stay is treated } \\
\text { individually }\end{array}$ \\
\hline \multirow[t]{4}{*}{ Starwood } & $\begin{array}{l}\text { Best rate guarantee for all } \\
\text { reservations }\end{array}$ & $\begin{array}{l}\text { Customer must find lower rate through any } \\
\text { reservation channel (not including opaque sites) } \\
\text { prior to or within } 24 \text { hours of booking; making a } \\
\text { reservation is not required }\end{array}$ \\
\hline & & $\begin{array}{l}\text { Starwood will honor the lower rate plus a } 10 \text { percent } \\
\text { discount or } 2,000 \text { frequent guest points }\end{array}$ \\
\hline & & Different room types may constitute valid claims \\
\hline & & Total cost of a multiple night stay is considered \\
\hline
\end{tabular}




\section{Exhibit 1:}

(continued)

\begin{tabular}{|c|c|c|}
\hline Best Western & $\begin{array}{l}\text { Low rate guarantee for web } \\
\text { site bookings only }\end{array}$ & $\begin{array}{l}\text { Customer must find lower rate online only within } \\
24 \text { hours of booking } \\
\text { Best Western will honor the lower rate plus an } \\
\text { additional } 10 \text { percent discount; extra discount does } \\
\text { not apply if the Best Western web site } \\
\text { subsequently offers the lower rate } \\
\text { Opaque travel web site rates will not be considered }\end{array}$ \\
\hline Hilton & $\begin{array}{l}\text { Best rate guarantee for any } \\
\text { reservation }\end{array}$ & $\begin{array}{l}\text { Customer must find lower rate online through any } \\
\text { reservation channel within } 24 \text { hours of booking } \\
\text { Hilton will match the lower rate and award customers } \\
\text { a } \$ 50 \text { American Express Gift Cheque } \\
\text { Reservation required } \\
\text { Opaque travel web site rates will not be considered }\end{array}$ \\
\hline Radisson & Best online rate guarantee & $\begin{array}{l}\text { Customer must find lower rate online only within } \\
24 \text { hours of booking } \\
\text { Radisson will honor the lower rate and give an addi- } \\
\text { tional } 25 \text { percent discount } \\
\text { Opaque travel web site rates will not be considered }\end{array}$ \\
\hline Holiday Inn & $\begin{array}{l}\text { Lowest Internet rate } \\
\text { guarantee }\end{array}$ & $\begin{array}{l}\text { Customer must find lower rate online only } \\
\text { Guarantee only valid for "best available" rate search } \\
\text { on the Holiday Inn web site } \\
\text { Holiday Inn will honor the lower rate and give an } \\
\text { additional } 10 \text { percent discount }\end{array}$ \\
\hline
\end{tabular}

the belief that customers should be quoted one price for a service package instead of several prices for aspects of a service package (Badinelli 2000). The study explained in this article tests that belief.

\section{Our Study}

We surveyed 153 travelers to determine whether customers preferred to be quoted different nightly rates for a single multiplenight hotel stay or one nightly rate for the entire stay. In this survey, we wanted to avoid the complications involved in the guarantee that goes with best available rates. The reason for our caution is the observation that we made above, that customers have frequently had problems enacting best available rate guarantees (Gilden 2005, 2004). Hotel chains and third-party web sites are disinclined to honor the BAR guarantee because they cannot always verify the lower rate found by customers on a competing web site. Also complicating the matter, customers can be confused by the detailed "fine print" that restricts the guarantee, typically by imposing time limits on making a claim or restricting sources of potentially competing rates (e.g., excluding rates obtained by calling the hotel directly or from certain reservation web sites). To sidestep this entire matter of BAR guarantees, we avoided using the term best available rates or BAR pricing as the subject of our study. Instead, we asked our respondents for their view of nonblended rates (meaning, best available rates) as compared to blended rates (meaning, traditional single-price approaches).

In particular, we wanted to determine whether being quoted a nonblended rate 
for each night of a multiple-night stay resulted in customers' having a more positive perception of the fairness, acceptability, reasonableness, and honesty of the pricing policy than if they were quoted a blended nightly rate. The use of a variable pricing strategy such as BAR pricing is possible when customers are willing to pay different prices for the same product (Dolan and Simon 1996). Hotels that use complex ratesetting systems must understand the value that customers place on the price of the service they are purchasing and communicate how customers' needs are being met through pricing policies. Therefore, as a gauge of the acceptability of variable pricing at hotels we tested customers' ratings of the following four measures: fairness, acceptability, reasonableness, and honesty. The outcome of that study would, we hoped, provide insight into what additional resources, if any, hotel chains should invest in the management and technology associated with implementing BAR pricing policies.

\section{Measures}

Fairness. Fairness is a consideration in rate setting, because customers generally support companies that practice fair pricing policies (Kahneman, Knetsch, and Thaler 1986; Thaler 1985). A fair pricing policy is one that is generally accepted by customers and perceived as justified for social or economic reasons. Fairness is especially important in setting prices for services because it is difficult for customers to evaluate their purchase in advance (Seiders and Berry 1998). Creating and sustaining positive perceptions of price fairness can lead to improved customer satisfaction and profitability (Kahneman, Knetsch, and Thaler 1986; Thaler 1985).

Acceptability. Along the same line, customers must accept the hotel's pricing structure. Even if customers find a business practice to be justifiable, they may not find it acceptable if the practice leads to an unequal balance between the customer's bargaining power and the firm's pricing power (Kahneman, Knetsch, and Thaler 1986). We tested for the acceptability of the two different pricing policies to capture this nuance. If company profits increase without a corresponding increase in customer value or customer value decreases without a matching decrease in price, business practices may be seen as unacceptable. Unacceptable practices include raising prices with no justification, providing inadequate information about the transaction, and failing to deliver the service as promised (Seiders and Berry 1998; Kahneman, Knetsch, and Thaler 1986).

Reasonableness. We also compared customers' perceptions of the reasonableness of blended and nonblended rates to determine whether our respondents view variable pricing as integral to the hotel reservation process. The usual gauge that customers use to judge fair and reasonable practices is that the practices do not significantly diverge from standard business practices (Kahneman, Knetsch, and Thaler 1986). Companies that use unreasonable practices have a poor reputation among potential customers.

Honesty. The final measure we tested in our study was the honesty of the two rate policies. Firms are expected to be socially responsible by not taking advantage of consumers, and a measure of this accountability to customers is how honest customers believe a firm to be (Maxwell 1995). However, customers may perceive some business practices to be honest but unfair, especially if customers find a company is misusing its market power and manipulating consumers (Kahneman, Knetsch, and Thaler 1986).

Gain versus loss. Our final consideration was whether our respondents considered the nonblended rates as a gain or a 
loss. We also wanted to discern whether respondents' perceptions of the two pricing schemes were affected by how the price structure was presented. Research has shown that customer perceptions improve when a price change is framed as a gain to the customer (Kahneman and Tversky 1979; Kimes 1994; Kimes and Wirtz 2003). However, these studies do not address the situation of BAR pricing, when prices change during a single service encounter. We tested the framing of price changes by quoting customers either a discount in the form of a high rate followed by a low rate, or a premium given as a low rate followed by a high rate, for successive nights of a hotel stay.

\section{Survey}

Our survey comprised 153 travelers at airports in Dallas, Texas; Pittsburgh, Pennsylvania; and Ithaca, New York. We asked respondents to participate as they waited to board planes, and we recorded a low incidence of people choosing not to participate. All survey responses were anonymous.

We presented four different scenariobased surveys to evaluate how our respondents reacted to blended and nonblended pricing policies. In all four scenarios, participants were told that they required a hotel reservation for a two-night, nonweekend stay; would like the lowest possible rate; and would be staying in the same room both nights. The survey scenarios differed according to pricing policy (blended or nonblended) and the framing of the pricing policy (premium or discount).

In the nonblended-rate scenario, respondents were quoted a different rate for each night of their stay. In the blended-rate scenario, respondents were quoted the same rate for both nights of their stay. This quoted rate was simply an average of the two different nights' rates.
The premium version of both the blended and nonblended scenarios stated that the hotel anticipated a busier second night, and so the lowest available rate on the first day was lower than the lowest available rate on the second day. The discount version of both the blended and nonblended surveys told participants that the hotel expected a slower second night, and so the lowest available rate on the first day was higher than the lowest available rate on the second day.

All questions for the four scenarios were identical, and each participant was randomly asked to evaluate only one of the four scenarios (that is, blended prices as a premium, blended prices as a discount, nonblended prices as a premium, or nonblended prices as a discount). We received from thirty-six to forty completed surveys for each of the four scenarios.

The questions included in the survey were single-item measures of respondents' perceptions of the fairness, acceptability, reasonableness, and honesty of the pricing policy in their assigned scenario. Each question was answered on a 7-point, Likert-type scale, with 1 and 7 representing extremes of each scale. For example, in the questions regarding fairness and reasonableness, 1 corresponded to extremely unfair or unreasonable, while 7 corresponded to extremely fair or reasonable. We reversed certain scales to help ensure valid results.

We also asked questions on how frequently our respondents stayed at a hotel, their level of familiarity with variable pricing at hotels, and their level of familiarity with BAR pricing. We also asked respondents to indicate how often they made reservations through three distribution channels (i.e., internet, calling the hotel directly, or calling the hotel's toll-free call center). Finally, we asked for demographic information, including nationality, age, and gender. Our respondents heavily comprised travelers from the United States and those over the 


\section{Exhibit 2:}

Characteristics of Survey Respondents (in percentages)

\begin{tabular}{|c|c|c|}
\hline Gender & Nationality & Age \\
\hline $\begin{array}{l}\text { Female-51 } \\
\text { Male }-49\end{array}$ & $\begin{array}{l}\text { United States }-85 \\
\text { International-15 }\end{array}$ & $\begin{array}{l}24 \text { and under- }-11.1 \\
25 \text { to } 34-45.1 \\
35 \text { to } 50-29.4 \\
51 \text { and over }-14.4\end{array}$ \\
\hline $\begin{array}{l}\text { Nights Stayed in a Hotel } \\
\text { over the Past Year }\end{array}$ & & $\begin{array}{c}\text { Reservation Channels Used to } \\
\text { Make Hotel Reservations }\end{array}$ \\
\hline $\begin{array}{l}\text { None }-1.3 \\
1 \text { to } 5-23.5 \\
6 \text { to } 10-32.7 \\
11 \text { to } 20-26.8 \\
\text { Over } 20-15.7\end{array}$ & & $\begin{array}{l}\text { Call the hotel directly } \\
\text { Never-13.1 } \\
\text { Sometimes-60.1 } \\
\text { Often-20.9 } \\
\text { Always-5.9 } \\
\text { Call the hotel's } 800 \text { number } \\
\text { Never-37.9 } \\
\text { Sometimes-55.6 } \\
\text { Often-6.5 } \\
\text { Always-0 } \\
\text { Use the internet } \\
\text { Never-11.8 } \\
\text { Sometimes-41.8 } \\
\text { Often-35.9 } \\
\text { Always-10.5 }\end{array}$ \\
\hline
\end{tabular}

age of twenty-five. All other demographic variables were relatively well distributed. Exhibit 2 presents the overall characteristics of survey respondents. Our findings are summarized in Exhibits 3 and 4.

\section{Results}

We analyzed the results of the survey using standard statistical models. ${ }^{1}$ Our respondents found neither pricing policy to be particularly appealing, as shown by the relatively low rating in Exhibit 3 . Nonblended rates garnered a neutral rating for fairness and reasonableness, but that was the highest score achieved on any measure. While these results seem to indicate that customers do not currently have a high opinion of hotel pricing policies, we collected no comments and cannot speculate on the reasons for the low ratings for the two pricing policies. Even though both systems seemed to be viewed dimly, our respondents gave higher marks to nonblended rates than to blended rates.

\section{Fairness}

Respondents rated the non-blended-rate scenario as significantly fairer than the blended-rate scenario. ${ }^{2}$ Interestingly, framing the price as a premium or a discount had no significant effect on the perceptions of fairness for either type of rate.

Age and familiarity with BAR pricing were found to affect fairness ratings. Of the four age groups (twenty-four and younger,

1. One-way and two-way additive ANOVA models were used to determine significant differences among and between average responses, as no interaction terms were found to be significant. Tukey's pairwise comparisons were used to estimate the differences among nonequal means. Regression analysis was used to control for the various demographic and background information provided by each subject.

2. All results are significant at a minimum of $p<.05$. 
Exhibit 3:

Survey Results

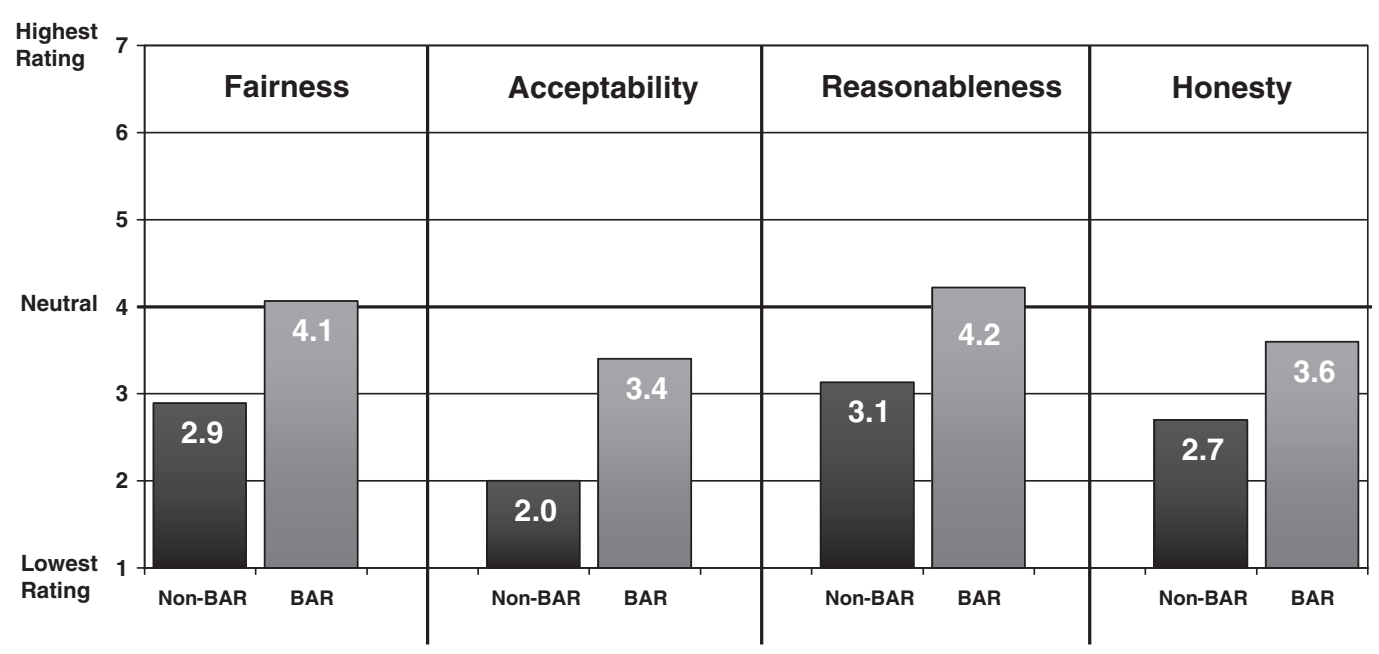

Note: $\mathrm{BAR}=$ best available rate

twenty-five to thirty-four, thirty-five to fifty, and fifty-one and older), the twenty-five to thirty-four age group rated nonblended rates as significantly fairer than blended rates. However, this finding could be due to a large sample size obtained for this age group. Participants who were unfamiliar with BAR pricing rated nonblended rates significantly fairer than blended rates. On the other hand, participants who were familiar with BAR pricing perceived no difference between the fairness of blended and nonblended rates.

\section{Acceptability}

Nonblended rates were rated as significantly more acceptable than blended rates. Again, the framing of the pricing policy had no significant impact on respondents' perceptions of the acceptability of either rate type.

Respondents between the ages of twentyfive and thirty-four considered nonblended rates significantly more acceptable than they did blended rates. Again, this finding may be the result of a larger sample size of survey respondents in this age range. As was the case with fairness, participants who were unfamiliar with BAR pricing found nonblended rates to be significantly more acceptable than blended rates. Likewise, participants who were familiar with BAR pricing found no significant difference in the acceptability of blended and nonblended rates.

\section{Fairness versus Acceptability}

Contrary to other research findings, in which fairness and acceptability are distinguished as two distinct measurements, our study revealed a strong correlation between respondents' ratings of the fairness of blended rates and their acceptability. That is, travelers who found the blended pricing policy to be unfair also found it to be unacceptable. ${ }^{3}$ On the other hand, we found no such correlation between fairness and acceptability relative to

3. $r=-.90$ 


\section{Exhibit 4:}

Summary of Findings by Measure

\begin{tabular}{|c|c|c|c|}
\hline Measure & Average & Standard Deviation & $\mathrm{N}$ \\
\hline \multicolumn{4}{|l|}{ Fairness } \\
\hline \multicolumn{4}{|l|}{ Non-BAR } \\
\hline Overall & 2.90 & 1.53 & 76 \\
\hline Premium & 2.78 & 1.49 & 40 \\
\hline Discount & 3.03 & 1.58 & 36 \\
\hline \multicolumn{4}{|l|}{ BAR } \\
\hline Overall & 4.07 & 1.29 & 77 \\
\hline Premium & 4.05 & 1.14 & 38 \\
\hline Discount & 4.08 & 1.44 & 39 \\
\hline \multicolumn{4}{|l|}{ Acceptability } \\
\hline \multicolumn{4}{|l|}{ Non-BAR } \\
\hline Overall & 1.99 & 1.87 & 76 \\
\hline Premium & 1.82 & 1.77 & 40 \\
\hline Discount & 2.17 & 1.98 & 36 \\
\hline \multicolumn{4}{|l|}{ BAR } \\
\hline Overall & 3.42 & 1.51 & 77 \\
\hline Premium & 3.10 & 1.59 & 38 \\
\hline Discount & 3.72 & 1.38 & 39 \\
\hline \multicolumn{4}{|c|}{ Reasonableness } \\
\hline \multicolumn{4}{|c|}{ Non-BAR } \\
\hline Overall & 3.13 & 1.57 & 76 \\
\hline Premium & 3.05 & 1.52 & 40 \\
\hline Discount & 3.22 & 1.64 & 36 \\
\hline \multicolumn{4}{|l|}{ BAR } \\
\hline Overall & 4.22 & 1.45 & 77 \\
\hline Premium & 4.13 & 1.44 & 38 \\
\hline Discount & 4.31 & 1.49 & 39 \\
\hline \multicolumn{4}{|l|}{ Honesty } \\
\hline \multicolumn{4}{|l|}{ Non-BAR } \\
\hline Overall & 2.70 & 1.50 & 76 \\
\hline Premium & 2.52 & 1.32 & 40 \\
\hline Discount & 2.89 & 1.67 & 36 \\
\hline \multicolumn{4}{|l|}{ BAR } \\
\hline Overall & 3.60 & 1.70 & 77 \\
\hline Premium & 3.37 & 1.79 & 38 \\
\hline Discount & 3.82 & 1.60 & 39 \\
\hline
\end{tabular}

Note: 1 is the lowest rating and 7 is the highest rating. BAR $=$ best available rate.

nonblended rates. ${ }^{4}$ As a result of these findings, we performed several additional statistical tests to determine whether respondents on the whole found significant differences between the perceived fairness and acceptability of the two scenarios..$^{5} \mathrm{We}$ did not find any substantial differences between perceptions of fairness and acceptability between blended and nonblended scenarios.

4. $r=.03$

5. These tests included a test for the equivalence of two proportions and a $t$-test on two independent populations of differences. 


\section{Reasonableness}

Our respondents rated blended rates as significantly less reasonable than nonblended rates. Once again, presenting the rates as either a premium or a discount had no effect on the perceived reasonableness of the two pricing policies. Also, infrequent travelers and respondents who were unfamiliar with BAR pricing considered nonblended rates to be significantly more reasonable than they did blended rates, but frequent travelers and respondents who were familiar with BAR pricing found no disparity between the reasonableness of blended and nonblended rates.

\section{Honesty}

Respondents rated nonblended rates as more honest than blended rates, but they saw no difference in honesty with rates presented as premiums or discounts. Unlike the other three measures, frequency of travel had an effect on customer perceptions of the honesty of blended and nonblended rates. Frequent travelers (those who had stayed at hotels more than twenty nights in the past year) found no significant difference between the honesty of blended and nonblended rates, while infrequent travelers rated nonblended rates as significantly more honest than blended rates. In this case, familiarity with BAR pricing, which had a significant impact on the rating of other variables, had no effect on respondents' perceptions of the honesty of either pricing policy.

\section{Implications of Study Findings}

Overall, our respondents prefer to be given full pricing information when booking hotel rooms, given that they rated nonblended rates as being more fair, acceptable, reasonable, and honest than blended rates. We also found that framing rates as either a discount or a premium had no effect on respondents' perceptions of either pricing policy. These results indicate that, when making a reservation for a multiple-night stay, travelers would rather be quoted the actual BAR for each night than an average nightly rate that conceals actual rates from night to night.

Managers should ensure that standard operating procedures connected with BAR pricing are fair and clear, so that propertylevel employees who may encounter guests dissatisfied with these rate policies can better manage guest perceptions. Explaining BAR rate policies and their restrictions to customers, as well as divulging the motivation behind these policies, allows guests to see those policies as reasonable, acceptable, and fair (Choi and Mattila 2003; Kimes 1994). Including a simple explanation such as "the lowest available rates over your stay differ each night because our hotel has several conferences staying here on those dates" may be a quick and easy way to provide customers with desired information and manage perceptions of price fairness.

We found that infrequent travelers view blended and nonblended rates in a different light than do frequent travelers. Frequent travelers found no difference in reasonableness between blended and nonblended rates, but infrequent travelers reacted more positively towards nonblended rates. This finding could indicate that BAR prices and policies may have become the reference prices and transactions for hotels, especially among travelers who use hotel services the most. The fact that frequent travelers do not appear to have a preference between being quoted a blended or nonblended rate could also indicate that frequent travelers may have an "anything goes" mentality toward hotel pricing. After all, many of them do not pay the actual bill. This finding may also reflect the overall low view that customers take of the consistency of hotel pricing. 
Given our findings, we suggest that hotels consistently quote the BAR for each night. We say this because infrequent travelers and those who had not heard of BAR pricing preferred nonblended rates, while frequent travelers and those familiar with BAR pricing seemed indifferent to the two pricing schemes. Thus, we feel that it would be prudent for managers to avoid confusion in hotel pricing, and particularly to avoid applying different pricing policies for different customers. We suspect that consistent pricing across all distribution channels might promote guests' trust of hotel pricing.

\section{Opportunities for}

\section{Further Study}

Our study was limited by its scenariobased design. It is possible that factors other than those found in our scenarios may also affect customers' perceptions of BAR pricing. One of these factors is the customer's purpose of travel (business or leisure) and, more to the point, who is responsible for paying hotel charges. Our respondents may have rated BAR pricing as being favorable under the assumption that they were paying for the room. Furthermore, the reasons why the nightly rates fluctuate may also influence perceptions of BAR pricing.

Even if rates are quoted per night, hotel guests may make their reservation decisions based solely on the total price that they will have to pay, instead of nightly rates. To determine customers' preferences for hotel rate quotes, further study may focus on perceptions of bundled prices versus perceptions of nonblended rates. This line of research would also be beneficial when customers are purchasing vacation and travel packages - such as bundling a hotel stay with airfare or car rental.

We close by underscoring our first finding, which is that our respondents were at best neutral toward both pricing policies.
This finding alone invites additional study. Hotel operators need to know why these respondents have such modest trust in obtaining fair and reasonable hotel prices and whether this pool of respondents is representative of hotel guests in general. In view of the tangle that airlines have made of their revenue management policies, hotel chains might be advised to avoid convincing their guests that pricing is a cynical exercise. This study argues for relative transparency in pricing, and for giving customers a chance to choose their rate for each night they stay in a particular property.

\section{Reference}

Badinelli, Ralph. 2000. An optimal, dynamic policy for hotel yield management. European Journal of Operational Research 121:476-503.

Carvell, Steven A., and Daniel C. Quan. 2005. Low-price guarantees: How hotel companies can get it right. CHR Reports 5(10).

Choi, Sunmee, and Anna S. Mattila. 2003. Hotel revenue management and its impact on customers' perceptions of fairness. Journal of Revenue and Pricing Management 2 (4): 303-14.

Dolan, Robert J., and Hermann Simon. 1996. Power pricing: How managing price transforms the bottom line. New York: Free Press.

Gilden, James. 2004. "Best rate" is not often so, so take advantage of that guarantee. Los Angeles Times, April 25.

- 2005. Hotels' special offers sometimes outdo their own best rates. Los Angeles Times, February 6.

Kahneman, Daniel, Jack L. Knetsch, and Richard H Thaler. 1986. Fairness as a constraint on profit seeking: Entitlements in the market. American Economic Review 76 (4): 728-41.

Kahneman, Daniel, and Amos Tversky. 1979. Prospect theory: An analysis of decision under risk. Econometrica 47 (2): 263-91.

Kimes, Sheryl E. 1994. Perceived fairness of yield management. Cornell Hotel and Restaurant Administration Quarterly 35 (1): 22-29.

Kimes, Sheryl E., and Jochen Wirtz. 2003. Has revenue management become acceptable? Findings from an international study on the perceived fairness of rate fences. Journal of Service Research 6 (2): 125-35.

KPMG. 2004. Global Hotel Distribution Survey 2004: Managing price and performance of channels to market. London: KPMG International.

Marcus, Benjamin, and Chris Anderson. 2006. Online low price guarantees-A real options analysis. Operations Research 54 (6): 1041-50. 
Maxwell, Sarah. 1995. What makes a price increase seem "fair"? Pricing Strategy \& Practice 3 (4): 21-27.

Seiders, Kathleen, and Leonard L. Berry. 1998. Service fairness: What it is and why it matters. Academy of Management Executive 12 (2): 8-20.

Thaler, Richard F. 1985. Mental accounting and consumer choice. Marketing Science 4 (3): 199-214.
Thompson, Gary M., and Alexandra Failmezger. 2005. Why customers shop around: A comparison of hotel room rates and availability across booking channels. CHR Reports 5(2).

Kristin V. Rohlfs (kvr3@cornell.edu) is a Ph.D. candidate at the Cornell University School of Hotel Administration, where Sheryl E. Kimes, Ph.D., is a professor of operations management (sek6@cornell .edu). 